International Journal of Engineering \& Technology, $7(2.13)(2018) 421-424$
International Journal of Engineering \& Technology
SPC
Website: www.sciencepubco.com/index.php/IJET
Research Paper

\title{
Performance Male and Female Drivers in Drowsiness System Based on Psychomotor Vigilance Task Test
}

\author{
Novie Theresia Br. Pasaribu ${ }^{1}$, Ratnadewi ${ }^{1 *}$, Agus Prijono ${ }^{1}$, Roy Pramono Adhie ${ }^{1}$, Winda Halim ${ }^{2}$, \\ Rainisa Maini Heryanto \\ ${ }^{1}$ Department of Electrical Engineering, Universitas Kristen Maranatha, Bandung, Indonesia
${ }^{2}$ Department of Industrial Engineering, Universitas Kristen Maranatha, Bandung, Indonesia
*Corresponding author E-mail: ratnadewi.bandung@gmail.com
}

\begin{abstract}
Driving on the highway that takes a long time and monotonous often causes the motorist or motorcycle to feel fatigue. Fatigue can be divided into two: physical or motoric fatigue and psychological or mental fatigue. As a result of this fatigue the driver may feel drowsiness, loss of concentration that endangers the safety of the driver. Some literature distinguishes gender in ability or driving skills. This paper observed and measured gender differences in driving. Measurements using Psychomotor Vigilance Task to measure mental fatigue before and after the driver were given an Arithmetic Stress Test. The data obtained on experimental drivers of male and female will then be processed using statistical tests to find out whether the psychomotor vigilance task of female and male drivers have same performance or not. Statistical tests were performed using Paired Sample T-Test. We have 17 drivers with 13 men and 4 women, each taken 5 session obtained that the T-test value of session 1 to session 5 have the same result that is the performance male and female drivers has the same performance in fatigue, but the number of male driver collisions smaller than the number of female driver collisions.
\end{abstract}

Keywords: Psychomotor Vigilance Task, T-test, Gender.

\section{Introduction}

The research on the ability of motorists has been done by [1] who observe the speed of motion, the use of mobile phones, breaking red lights, not using seat belt, breaking queues, etc. on male and female drivers in Malaysia. In this research [2] [3] used questioner method and analyzed with t-test and chi square.

The research on sleepiness has been done by [4] Sheng detects sleepiness and applies it to control the manual machine and automatic machine when the driver is drowsy. This is done so that the safety of drivers can be further improved.

The measurements would use Psychomotor Vigilance Task (PVT), Dinges and Powell, 1985). PVT is often used in research to measure the effect of sleep loss that causes a decrease in a person's alertness due to micro sleep, but the measurement using PVT has various variations in research related to the results given and the duration of the tests performed. Experimental would be founded the mean with formula $1 / \mathrm{RT}^{*} 1000$ (response time).

The research using PVT[2], [3], [5], [6] on laboratory experiments to observe sleep deprivation has been done for $90 \mathrm{sec}, 5 \mathrm{~min}$, and $10 \mathrm{~min}$. The analysis results using $90 \mathrm{sec}$ PVT is not sufficient to observe sleep deprivation, while $5 \mathrm{~min}$ and $10 \mathrm{~min}$ can be used to observe sleep deprivation. We can select 5 min and 10 min PVT depending on requirement. The PVT $5 \mathrm{~min}$ has correlation equal to $10 \mathrm{~min}$. Another research about $3 \mathrm{~min}$ PVT and $10 \mathrm{~min}$ PVT studies have also been performed, [5] and it is found that $3 \mathrm{~min}$ PVT still has to be improved.

The research on gender and age groups of workers using PVT. Male motion speed is faster compared to female because the fe- male often holds her reaction to be more accurate[5]. This research contributed to use PVT Test \& Arithmetic Stress Test to test the drowsiness of the driver by observing the number of collisions occurring while driving.

\section{Method}

Psychomotor Vigilance Task (PVT) test is a measurement of the speed of one's reaction time to a visual stimulus. Quantitative dependent variables involve errors due to omissions reflecting fluctuations in endogenous cognitive conditions. Research shows that increased sleepiness correlates with worsening alertness, problem-solving ability to slow down, decreased psycho-motor skills, and increase the wrong response rate.

Vigilance is a process of alacrity equipped with various kinds of information and a quick response to overcome problems that occur [7], the decreases work performance due to the vigilance task due to the declining source of information processing and not because it weakens power or power. Based on research Grier et.al [8] at least there are 4 things that affect vigilance, namely: the declining ability of information processing, repetition of tasks with long periods of time, individual control and excessive workload [9].

The first PVT was studied by David F. Dinges [5] and is popular because of its simplicity in value assignment, simple metrics, and convergent validity. PVT has a learning curve with only 1-3 experimental trials and a 10-minute variant has become a standard laboratory tool for assessing sustainable performance. However, PVT shows that motivation can counter the adverse effects of sleep deprivation by up to 36 hours. 
The PVT test is a simple task where the subject pushes the button as fast as it can when the light is on. The lights will fire randomly every few seconds for 5-10 minutes. After the button is pressed it will show the reaction time in milliseconds (milliseconds). Although the subject is required to press the button as fast as possible but the subject should not press the button too quickly because it will be considered as false start (FS).

In the Dinges [10] study, the main measurement of this task is not to assess reaction time, but to see how many times the button is not pressed when the light is on. The purpose of Dinges PVT is to measure sustained attention, and provide a numerical measure of sleepiness by counting the number of irregularities in the attention of the subject under test. The basic idea of research conducted by Dinges is the need for sustained attention while doing long-term work, it is then linked to bedtime from someone, and how the sleep time then affects the attention and vigilance of that person. The study involved 41 healthy drivers.

Gregory D. Roach, Drew Dawson, and Nicole Lamond [11] conducted a study to determine whether PVT measurements with shorter durations of time could be used to replace 10-minute PVT, in which the drivers used were 11 women and 5 men, average age of 21.7 years. The measurements were done with PVT 10 minutes, 5 minutes, and 1.5 minutes and looked for correlations between 3 measurements performed, so obtained the measurement results with PVT 5 minutes has a high correlation with PVT 10 minutes, so PVT 5 minutes can be used to replace PVT 10 minutes. Sylvia Loh [12] also discussed the validity of the use of standard PVP 10 minutes and compared it with PVT 5 minutes, and 2 minutes with 15 drivers consisted of 7 men and 8 women. The research was conducted by observing the use of PVT 10 minutes, 5 minutes, and 2 minutes by measuring 4 matrix of performance i.e. average reaction time, $10 \%$ fastest reaction time, error percentage, $10 \%$ slowest reaction time. The results obtained are 5 minutes PVT measurement can be used as an alternative to measure reaction time.

But in its development, measurement of reaction time does not require a special tool but can use computer media with a program that randomly generates random numbers. Subjects can be reacts by pressing a button on the mouse or touch pad, so that number stops and shows the reaction time number in milliseconds.

On measurement use PVT the numbers appear in units of milliseconds. If the reaction time (Reaction Time (RT)) that appears has a value less than 100 (RT $<100$ milliseconds) then the data is considered invalid or false start, because this figure is considered as a number that appears without any stimulus. RT $<100$ milliseconds can also appear due to pressing the button at the wrong time and failing to release the button more than 3 seconds or more. Meanwhile, reaction time greater than 500 (RT> 500) will be considered as lapses, which occurs when the driver's condition is not vigilant such as daydreaming or micro sleep [5].

In PVT studies there are several frequently used parameters such as mean, $10 \%$ fastest reaction time, $10 \%$ slowest reaction time, number of lapses (number of reaction times having value greater than 500) other [13].

The Proposed Drowsiness Detection System processes design summarized in Fig 1. First, the drivers are having PVT-1 Test (5 minutes), and then driver continue to having driving process (2 minutes). Next, the drivers are given PVT-2 Test (5 minutes) and driving process (10 minutes). Then the drivers are given PVT-3 Test. After this the drivers are given Arithmetic Stress Test for 30 minutes. The purpose of Arithmetic Stress Test is to give the drivers feel fatigue. Then, continue process for PVT-4 Test (5 minutes) and after that driving process for 30 minutes (consist of 3 times driving process, each process 10 minutes), and the last process the drivers are given PVT-5 Test.

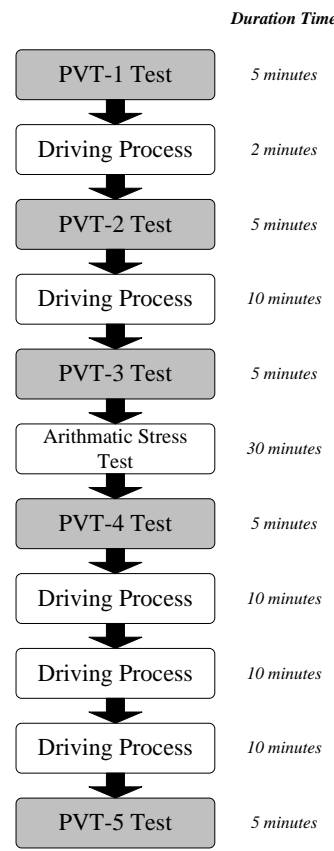

Fig. 1: Design Process of Drowsiness Detection System based on PVT Test \& Arithmetic Stress Test

All the drivers have the good healthy condition before the experiment and at the time of driving process, the numbers of collisions that occur are counting.

\section{Result and Discussion}

Based on traffic accidents data from KORLANTAS POLRI (Indonesian Police) in 2017 were showed accident rate based on age category. The first rating on age category is 15-19 years old, the second rating is 20-24 years old, the third rating is 25-29 years old [14]. In this research, subjects consisted of 17 respondent, $4 \mathrm{fe}-$ male (Fig. 2) and 13 male (Fig. 3), age between 19-27 years old. The experiments were performed in the laboratory with an average room temperature of $21^{\circ} \mathrm{C}$ and an average humidity 50 and lux light 170.

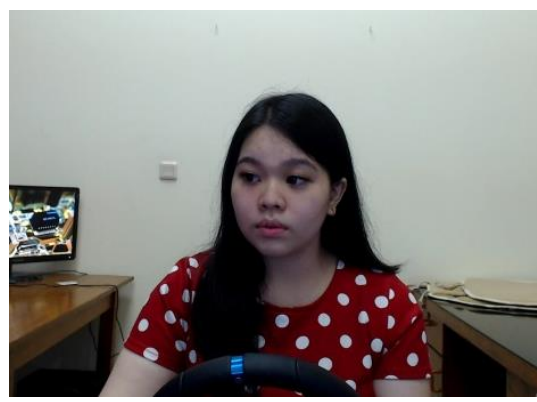

Fig. 2: Sample Female Driver

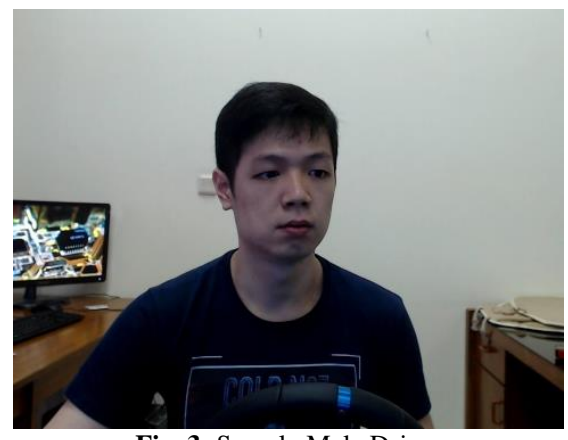

Fig. 3: Sample Male Driver

The experiments time is having duration of 97 minutes. Before testing the driver had driving exercises with the simulator device (Fig. 4). 


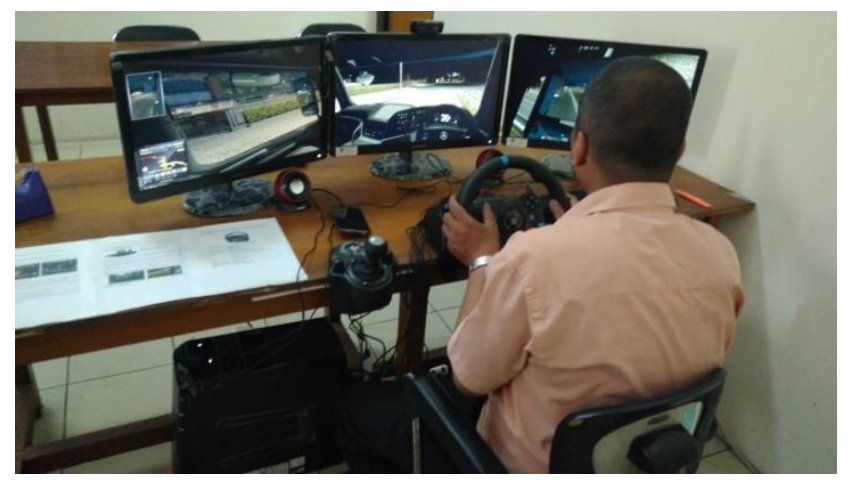

Fig. 4: Driver Simulator Device in Laboratory

Data analysis of male and female drivers was conducted using two-tailed statistical test. The t Test is commonly used to compare one group or one set of scores to another. In this research, female group compare with male group. The Independent t-Test can be used to statistically compare these average scores. The null hypotheses $H_{0}$ is male PVT equal to female PVT. Hypotheses $H_{1}$ is male PVT is not the same as female PVT. The number of driver in sample $(N)$ is 17 persons. The number of group female is 4 persons $\left(n_{1}\right)$, the number of group male is 13 persons $\left(n_{2}\right)$. Degrees of freedom 15 equal to $\left(n_{1}-1\right)+\left(n_{2}-1\right)$ or $N-2$. Alpha is 0.05 . As with other test statistics, the evaluation of a t statistic involves comparing the observed value of $t$ with the critical value of $t$ for the null hypothesis being tested. The critical value of $t$, in turn, depends on three things: the type of hypothesis being tested (e.g., traditional vs. minimum-effect test), the alpha level, and the $\mathrm{N}=$ number of individuals in sample; $N=$ number of individuals in each independent group. Fig. 1 shows the area $H_{0}$ and $H_{1}$ accepted or rejected based on critical value of $t$.

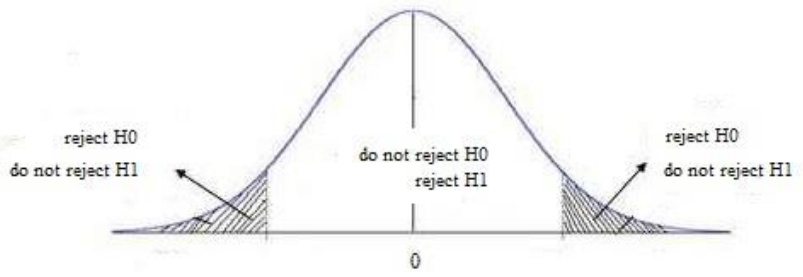

Fig. 1: Area does not reject or reject $\mathrm{H}_{0}$ or $\mathrm{H}_{1}$

Table 1 show T-test of PVT-1 female and male. t-stat value (1.27) smaller than t critical two-tail (2.13), it can be concluded that the value do not reject $H_{0}$ meaning that male PVT equal to female PVT. Gender does not affect PVT.

Table 1: Data on T-test PVT-1 Results of Male Sample Groups and Female Sample Grups

\begin{tabular}{l|r|r|}
\multicolumn{1}{|c|}{ PVT-1 } & \multicolumn{1}{c|}{ Variable 1 } & Variable 2 \\
\hline Mean & 3.15 & 3.35 \\
\hline Variance & 0.09 & 0.07 \\
\hline Observations & 4.00 & 13.00 \\
\hline Pooled Variance & 0.08 & \\
\hline Hypothesized Mean Difference & 0.00 & \\
\hline df & 15.00 & \\
\hline t Stat & -1.27 & \\
\hline P(T<=t) one-tail & 0.11 & \\
\hline t Critical one-tail & 1.75 & \\
\hline P(T<=t) two-tail & 0.22 & \\
\hline t Critical two-tail & 2.13 & \\
\hline
\end{tabular}

Table 2 showed the process of PVT-2 female and male using Ttest. t-stat value (-0.33) smaller than t critical two-tail (2.13), it can be concluded that do not reject $H_{0}$ meaning that male PVT equal to female PVT. Gender does not affect PVT.
Table 2: Data on T-test PVT-2 Results of Male Sample Groups and Female Sample Groups

\begin{tabular}{|l|r|r|}
\hline \multicolumn{1}{|c|}{ PVT-2 } & Variable 1 & \multicolumn{1}{c|}{ Variable 2 } \\
\hline Mean & 3.06 & 3.19 \\
\hline Variance & 0.14 & 0.57 \\
\hline Observations & 4.00 & 13.00 \\
\hline Pooled Variance & 0.48 & \\
\hline Hypothesized Mean Difference & 0.00 & \\
\hline Df & 15.00 & \\
\hline t Stat & -0.33 & \\
\hline P(T<=t) one-tail & 0.37 & \\
\hline t Critical one-tail & 1.75 & \\
\hline P(T<=t) two-tail & 0.75 & \\
\hline t Critical two-tail & 2.13 & \\
\hline
\end{tabular}

Table 3 show the process of PVT-3 of female and male using Ttest. t-stat value (-1.14) smaller than $t$ critical two-tail (2.13), it can be concluded that the value do not reject $H_{0}$ meaning that male PVT equal to female PVT. Gender does not affect PVT.

Table 3: Data on T-test PVT-3 Results of Male Sample Groups and Female Sample Grups

\begin{tabular}{|l|r|r|}
\hline \multicolumn{1}{|c|}{ PVT-3 } & Variable 1 & Variable 2 \\
\hline Mean & 3.03 & 3.28 \\
\hline Variance & 0.18 & 0.13 \\
\hline Observations & 4.00 & 13.00 \\
\hline Pooled Variance & 0.14 & \\
\hline Hypothesized Mean Difference & 0.00 & \\
\hline Df & 15.00 & \\
\hline t Stat & -1.14 & \\
\hline P(T<=t) one-tail & 0.14 & \\
\hline t Critical one-tail & 1.75 & \\
\hline P(T<=t) two-tail & 0.27 & \\
\hline t Critical two-tail & 2.13 & \\
\hline Table 4 shows process & & \\
\hline
\end{tabular}

Table 4 shows process of T-test of PVT-4 female and male. t-stat value (-0.60) smaller than t critical two-tail (2.13), it can be concluded that the value do not reject $H_{0}$ meaning that male PVT equal to female PVT. Gender does not affect PVT.

Table 4: Data on T-test PVT-4 Results of Male Sample Groups and Female Sample Groups

\begin{tabular}{|l|r|r|}
\hline \multicolumn{1}{|c|}{ PVT-4 } & Variable 1 & \multicolumn{1}{c|}{ Variable 2 } \\
\hline Mean & 3.08 & 3.23 \\
\hline Variance & 0.24 & 0.18 \\
\hline Observations & 4.00 & 13.00 \\
\hline Pooled Variance & 0.19 & \\
\hline Hypothesized Mean Difference & 0.00 & \\
\hline df & 15.00 & \\
\hline t Stat & -0.60 & \\
\hline P(T<=t) one-tail & 0.28 & \\
\hline t Critical one-tail & 1.75 & \\
\hline P(T<=t) two-tail & 0.56 & \\
\hline t Critical two-tail & 2.13 & \\
\hline
\end{tabular}

Table 5 show the process of PVT- 5 female and male using T-test. $\mathrm{t}$-stat value (-1.03) smaller than t critical two-tail (2.13), it can be concluded that the value do not reject $H_{0}$ meaning that male PVT equal to female PVT. Gender does not affect PVT.

In this study we observed the number of average collisions conducted by male and female drivers from observations of researchers at session 1 until session 5 (Table 6). The null hypotheses $H_{0}$ is the number of male driver collisions equals the number of female driver collisions, and $H_{1}$ is the number of male driver collisions smaller than the number of female driver collisions. We obtained a t-stat value (2.56) bigger than t critical one-tail (1.75), it can be concluded that the value reject $H_{0}$ meaning that the number of male driver collisions smaller than the number of female driver collisions.

Table 5: Data on T-test PVT-5 Results of Male Sample Groups and Female Sample Groups

\begin{tabular}{|l|r|r|}
\hline \multicolumn{1}{|c|}{ PVT-5 } & \multicolumn{1}{|c|}{ Variable 1 } & \multicolumn{1}{c|}{ Variable 2 } \\
\hline Mean & 2.88 & 3.12 \\
\hline Variance & 0.24 & 0.14 \\
\hline Observations & 4.00 & 13.00 \\
\hline Pooled Variance & 0.16 & \\
\hline
\end{tabular}




\begin{tabular}{|l|r|l|}
\hline Hypothesized Mean Difference & 0.00 & \\
\hline $\mathrm{df}$ & 15.00 & \\
\hline $\mathrm{t}$ Stat & -1.03 & \\
\hline $\mathrm{P}(\mathrm{T}<=\mathrm{t})$ one-tail & 0.16 & \\
\hline $\mathrm{t}$ Critical one-tail & 1.75 & \\
\hline $\mathrm{P}(\mathrm{T}<=\mathrm{t})$ two-tail & 0.32 & \\
\hline $\mathrm{t}$ Critical two-tail & 2.13 & \\
\hline
\end{tabular}

Table 6: Data on T-test average collisions conducted by Male and Female drivers

\begin{tabular}{|l|r|r|}
\hline \multicolumn{1}{|c|}{ collision } & \multicolumn{1}{c|}{ Variable 1 } & \multicolumn{1}{c|}{ Variable 2 } \\
\hline Mean & 3.20 & 1.25 \\
\hline Variance & 5.38 & 0.87 \\
\hline Observations & 4.00 & 13.00 \\
\hline Pooled Variance & 1.77 & \\
\hline Hypothesized Mean Difference & 0.00 & \\
\hline df & 15.00 & \\
\hline t Stat & 2.56 & \\
\hline $\mathrm{P}(\mathrm{T}<=\mathrm{t})$ one-tail & 0.01 & \\
\hline $\mathrm{t}$ Critical one-tail & 1.75 & \\
\hline $\mathrm{P}(\mathrm{T}<=\mathrm{t})$ two-tail & 0.02 & \\
\hline $\mathrm{t}$ Critical two-tail & 2.13 & \\
\hline
\end{tabular}

\section{Conclusion}

The experimental results from five PVT of 17 male and female drivers can be concluded that male and female performance is the same (based on PVT test). From the observations researchers the number of collisions male drivers smaller than the number of collisions female drivers.

\section{References}

[1] S. Liew, R. Hamidun, and N. F. Mohd Soid, "Differences of Driving Experience and Gender on Traffic Offences among Malaysian Motorists," MATEC Web Conf., vol. 103, 2017.

[2] K. R. Murphy, B. Myors, and A. Wolach, Statistical Power Analysis, Fourth. New York: Taylor \& Francis, 2014.

[3] S. W. Huck, Reading Statistics and Research, Sixth. Boston: Pearson Education, Inc., 2012.

[4] W. Sheng, Y. Ou, D. Tran, E. Tadesse, M. Liu, and G. Yan, "An integrated manual and autonomous driving framework based on driver drowsiness detection," IEEE Int. Conf. Intell. Robot. Syst., pp 4376-4381, 2013.

[5] M. Basner and D. F. Dinges, "Maximizing sensitivity of PVT to Sleep Loss," Sleep, vol. 34, no. 5, pp. 581-591, 2011.

[6] W. Halim, "Evaluasi Penggunaan Psychomotor Vigilance Task dalam Konteks Pengukuran Beban Kerja Mental," Institut Teknologi Bandung, 2012.

[7] F. M. Donald, "The classification of vigilance tasks in the real world," Ergonomics, vol. 51, no. 11, pp. 1643-1655, 2008.

[8] R. A. Grier et al., "The Vigilance Decrement Reflects Limitations in Effortful Attention, Not Mindlessness," Hum. Factors J. Hum. Factors Ergon. Soc., vol. 45, no. 3, pp. 349-359, 2003.

[9] J. Mathis and C. W. Hess, "Sleepiness and vigilance tests," Swiss Med. Wkly., vol. 139, no. 15-16, pp. 214-219, 2009.

[10] D. F. Dinges, W. G. Whitehouse, E. C. Orne, and M. T. Orne, "The benefits of a nap during prolonged work and wakefulness," Work Stress, vol. 2, no. 2, pp. 139-153, 1988.

[11] H. Inkeri, "Fatigue while driving in a car simulator: Effects on vigilance performance and autonomic skin conductance," no. March, 2010.

[12] S. Loh, N. Lamond, J. Dorrian, G. Roach, and D. Dawson, "the Validity of Psychomotor Vigilance Tasks of Less," vol. 36, no. 2, pp. 339-346, 2004.

[13] I. S. Lee, W. A. Bardwell, S. Ancoli-Israel, and J. E. Dimsdale, "Number of lapses during the psychomotor vigilance task as an objective measure of fatigue," J. Clin. Sleep Med., vol. 6, no. 2, pp. 163-168, 2010.

[14] K. POLRI, “Accident Data," Injury Type. . 